Laboratorio de Arte,1-1988 http://dx.doi.org/10.12795/LA.1988.i01.15

\title{
NOTAS A UNA EXPOSICION OBLIGADA: REMEDIOS VARO O EL PRODIGIO REVELADO
}

Fernando Martín Martín

Ultimamente y con frecuencia, se suele señalar y calificar refiriéndose a algunos acontecimientos que han sucedido en España, de "hito Histórico",esto aplicado al mundo del arte, creo que hoy cobra una especial relevancia y exactitud, pues la exposición de Remedios Varo patrocinada por la Fundación Banco Exterior con sede en Madrid, constituye un auténtico hito que nos devuelve a una de las artistas de mayor talento y creatividad del arte contemporáneo español, a la par que más desconocida. De ahí que su recuperación no sólo era a todas luces necesaria, sino que ello repara una injusticia moral. Hasta ahora, ni en España ni en el resto de Europa, se había celebrado ninguna exposición individual, siendo esta la primera retrospectiva que con carácter antológico se efectúa, coincidiendo con el ochenta aniversario de su nacimiento (1).

Después de casi tres años de preparación en los que no han faltado avatares de toda índole - basta decir que al final casi se trastoca la exposición debido a la inundación en el museo mexicano donde se hallaban provisionalmente depositados parte de sus cuadros- se han conseguido reunir un total de ochenta y dos obras entre óleos, dibujos y "gouaches", el más antiguo fechado en 1924, pertenecientes a los dos periodos, español y mexicano, en que se puede dividir su producción, dando un mayor énfasis a la

(1) Con ocasión de la exposición patrocinada por la Fundación Banco Exterior - Remedios Varo-, Noviembre, 1988-Enero, 1089, Madrid, se ha editado junto al excelente catálogo una completa e importante monografla debida a la investigadora norteamericana Janet Kaplan, Viajes inesperados, el arte y la vida de Remedios Varo, Abbeville Press, Nueva York, 1988. Anteriormente a estas publicaciones, la bibliografla sobre esta artista espanola era bastante escasa, destacando entre ella el texto de Roger Callois, Octavio Paz y Juliana González, Remedios Varo, Ed. Era, México, 1966, y Edouar Jaguer, Remedios Varo, Filipacchi, Parls, 1980. 
etapa mexicana, por ser ésta donde la personalidad y estilo de Remedios Varo se hace más definido.

En cuanto al montaje realizado, se aprecia una bien cuidada y brillante opción por la alternancia cronológica y temática de la obra, evitando un discurso lineal en su presentación. En este sentido, es de resaltar la labor llevada a cabo por la fotógrafa Marisa González, en su bello diseño de estructura poligonal que sirve de apoyo y base expositiva a dibujos e iconografía de Remedios Varo, haciendo con ello una clara alusión formal a las arquitecturas que pueden verse en algunos fondos de sus cuadros, concretamente a la torrezigurat visible en la espléndida composición titulada El Flautista.

Nacida en Anglés, provincia de Gerona, en 1908, y formada en la madrileña Academia de San Fernando, Remedios Varo es junto con Joan Miró, Salvador Dalí y el canario Oscar Domínguez, la aportación más importante que ha dado España al movimiento surrealista. Perteneciente a ese reducido, pero cualificado grupo de artistas que integran nuestra vanguardia histórica, Remedios Varo, lo mismo que Esteban Francés y Eugenio Granell, fue uno de los pocos artistas que tuvieron una relación más temprana con el núcleo surrealista de París. No en vano le unió amistad con Benjamín Peret, André Bretón y conoció a Paul Eluart, Max Emst o Leonora Carrington, participando en exposiciones y actividades del grupo surrealista. Esta característica, además del hecho de haber desarrollado gran parte de su obra fuera de España, ha contribuido a que el surrealismo en la obra de Remedios Varo fuese una constante, diferencia esencial con respecto a la mayoría de sus compatriotas, los cuales por motivos y circunnstancias diversas, su adhesión al surrealismo fue temporal, pienso en Maruja Mallo, Angeles Santos o Adela Tejero, por citar a artistas que como ella se dieron a conocer a finales de los veinte y principios de los treinta.

De personalidad acusada, Remedios Varo era una mujer inteligente, sensible y muy observadora, absorta en su mundo interior, un mundo en continua especulación imaginativa y abierto a cualquier acontecimiento o suceso que proviniese del exterior, el cual adquiría rápidamente para ella un significado profundo que luego trataría de traducir y llevar a sus cuadros.

Artista de gran capacidad de trabajo, se entregaba siete u ocho horas diarias en su estudio aislada y durante meses. Muchos de los personajes femeninos que aparecen en sus cuadros, son una suerte de autorretratos que adoptan sus rasgos -cabello largo, rostro triangular, ojos almendrados- y, sobre todo, viven experiencias y deseos que son una traslación de sus ideas e inquietudes.

Nadie como Remedios Varo ha hecho realidad la frase de Bretón, "Sólo lo maravilloso es bello, no hay belleza sin lo maravilloso". El arte de 
Remedios posee la cualidad de hacerse sentir antes de haberse comprendido. Enmarcada dentro del surrealismo fantástico, la obra de Remedios destaca por su originalidad y fuerte personalidad. Pintura donde se mezcla un tono romántico con un fascinante sentido poético contenedor de un sutil poder de evocación. Lejos de todo automatismo, el surrealismo de Remedios es figurativo y narrativo, siempre hay un tema predominante, en el que, lentamente, parecen haberse posado en el lienzo, a modo de revelaciones, insólitas imágenes que son representadas de forma detallada y minuciosa. Uno de los rasgos más acusados de la obra de Remedios, es su perfecto dominio de la técnica, manifestada tanto en el dibujo como en el uso del color, que son aplicados con verdadero oficio de miniaturista digno de una tabla flamenca. Esta depuración en el dibujo que define perfiles, unida a ese carácter cercano al hacer de los iluminadores medievales, confieren a muchos de sus cuadros una categoría de verdadera joya en su sentido literal. El formato por lo general pequeño, el añadido de placas de nácar o marfil -"El Flautista", 1955; "Ermitaño", 1956, y "Lady Godiva", 1956 - convierten a ciertas obras de Remedios en objetos preciosos a la manera de iconos.

En el universo pictórico de Remedios no hay sitio para el horror, la angustia o la agresividad, tan notoria en el ámbito fantástico de Leonora Carrington y otras surrealistas . Por el contrario, las historias prodigiosas que se nos cuentan, están presididas por la armonía y serenidad de las situaciones, sean de sorpresa o de carácter mágico. Una armoniosidad que abarca incluso lo cromático, no existiendo estridencias ni bruscos contrastes en el color. Diríase que la atmósfera de quietud y sosiego es la condición propicia para la aparición del sueño o la revelación.

La figura humana es constante en toda la producción de Remedios. Los distintos elementos que vemos en sus composiciones están tomados por lo común del mundo real y cotidiano, sin embargo sufren metamorfosis elevándoles a una dimensión feérica. Como obra inscrita en los principios surrealistas, sus pinturas contienen las peculiaridades propias de este estilo, como es la unión de contrarios, reflejada aquí en la fusión de reinos, sobre todo entre arquitectura y naturaleza o entre lo orgánico y lo inerte.. Así, el mundo vegetal cumplirá funciones artificiales - Catedral Vegetal, 1957- o invadirá estancias donde crecen plantas y flores a través de las baldosas del suelo o trepando por grietas de las paredes como enrredaderas de un jardín, rompiendo de este modo la frontera de lo exterior e interior: Las Horas Muertas, 1956; Armonía, 1956. Del mismo modo, la descontextualización del objeto de la pintura surrealista, en su desafío a las leyes de la lógica y suprema arbitrariedad, aparece en la obra de Remedios como en Mimetismo, 1960, donde los objetos cobran vida propia y el ser 
humano, en este caso una mujer, se transforma en un sillón ante la mirada escrutadora de un gato que desde una hendidura del suelo observa el fenómeno; mientras, en el fondo de la habitación la puerta de un armario se entreabre dejando escapar nubes en un efecto muy de Magritte, a la vez que la pata de una silla, como si fuese un brazo, retira de un cajón un pañuelo.

Uno de los "reproches" más repetidos que se le han hecho al surrealismo es el carácter literario que buena parte de su pintura posee, algo igualmente dicho por algunos que se han acercado a la obra de Remedios Varo. Ciertamente el arte de Remedios es sumamente literario y descriptivo, entre otros motivos porque se dedicó a dar apariencia a los sueños y visualizar historias fabulosas con el mismo espíritu que inspiró al artista anónimo el bellísimo tapiz de la Dama del Unicornio que actualmente guarda el Museo de Cluny. Sin embargo, esta acusación más que una censura, es, a mi entender, un elogio que marca la diferencia y la originalidad entre los seguidores de un surrealismo basado casi exclusivamente en el desplazamiento de figuras y objetos fuera de su contexto y el consiguiente impacto que provoca dicha elección gratuita.

En una obra como la de Remedios donde el contenido argumental es de carácter maravilloso, los protagonistas adquieren un valor excepcional, tanto por sus cometidos como por su propia naturaleza fantástica. Personajes de muy variada forma y condición, predominando los femeninos en cuyo caso, como he advertido anteriormente, adoptan rasgos parecidos con su autora. Cuadros como: "Encuentro", 1959, donde la protagonista al abrir -un pequeño cofre halla su propio rostro; El camino árido, 1962, en el que el personaje aparece andando por un sendero pedregoso y hostil o Cirujía plástica, en el que una dama acude a los servicios quinírgicos a remediar su complejo de Cyrano de Bergerac, son tres referencias autobiográficas de Remedios Varo que aluden respectivamente, a la soledad espiritual en que se encontraba, a su incesante búsqueda por encontrar una vía superior, y al tamaño de su nariz que tanto le preocupó. Los personajes masculinos, teniendo la misma complexión delgada y delicada que los femeninos, presentan una mayor variedad tipológica y expresiva. Su apariencia es asexuada o andrógica, estando ocupados, en su mayoría, a la investigación científica o esotérica: astrónomos, alquimistas o magos, aparecen entregados afanosamente a tareas maravillosas en la soledad y quietud de su estudio, en una atmósfera de intimidad y recogimiento: La revelación o el relojero, 1955; Armonía, 1956; Planta insumisa, 1961. En otras ocasiones los personajes aparecen como viajeros o exploradores en pleno tránsito, nunca inmóviles a la manera de los de Delvaux o Margritte, deambulando por 
bosques o navegando por ríos a través de medios de locomoción fantásticos, cuya apariencia trae a la memoria los artilujios del Bosco. Extraordinarios artefactos de timón y hélices con aspas livianas que sirven para conducir a individuos de expresión impávida que se dirigen presurosos a una cita inaplazable. Frágiles embarcaciones, velocípedos, roulottes de múltiples ruedas y aparatos eólicos, que son movidos con precisión exacta por elementos naturales como el viento o por complejos engranajes mecánicos: Roulotte, 1956; Tránsito en espiral, 1960. Otras veces el medio de transporte puede ir inserto en la propia anatomía del personaje: El Vagabundo, 1958. En este inventario de personajes existen aquellos cuyas peculiaridades fantásticas les hacen pertenecer al reino de lo sobrenatural, seres híbridos, de naturaleza ambigua, cuerpos inmateriales o transparentes que dejan ver moradas arquitectónicas, Las horas muertas, 1956, o simplemente vacíos, cuya conformación viene dada por atuendos de difícil catalogación material que va de lo vegetal al harapo: Ermitaño, 1956; Música solar, 1955. Por algunos de estos cuerpos, como ha advertido Octavio Paz, "no circula sangre sino luz", personajes que a veces apenas tocan el suelo con sus pies, levitan y flotan.

A semejanza de Giorgio de Chirico, uno de los puntos de mayor interés y atracción en la pintura de Remedios, es el paisaje que sirve de escenario al mundo mágico creado por esta autora. Paisajes urbanos al aire libre o lacustres, aparecen como telón de fondo o acotación espacial al fenómeno maravilloso. En ellos y de un modo especial sobreslen arquitecturas que pueden englobarse por sus características formales y estilísticas en el área medieval., bien en su faceta románica o gótica, compuesta por edificios de pesados muros a la manera de fortalezas o torreones de planta centrada y poligonal: Banqueros en acción, 1962; La Tejedora de Verona, 1956, o Bordando el manto terrestre, imagen esta última que nos recuerda a la composición de Angeles Santos Un Mundo, 1929. En los ejemplos citados existe la visión simultanea exterior e interior como en la pintura flamenca o primitiva italiana, permitiendo percibir la acción que se desarrolla en las distintas estancias a la manera de las casas de muñecas de juguete. Sus interiores suelen ser de gran austeridad, de paredes desnudas y ventanales en arco por donde a veces se establece la comunicación sobrenatural con el cosmos: Relojero o la revelación, Creación de las aves, 1958. Arquitectura en las que sólo vemos una síntesis de lo medieval y lo renacentista, esta última expresada sobre todo en el uso de rítmicas arcadas agrupadas de tres en tres: El malabarista, 1956, o balaustres que coronan extraños palacios; Ruptura, 1955, ofrecen una coexistencia de una arquitectura real o inventada. Quizá la obra maestra y más 
representativa donde la arquitectura cobra un papel relevante, sea esa ciudadisla que lleva por título Tránsito en espiral, de 1962, ciudad configurada a modo de laberinto helicoidad, proyectada de forma continua por torres de estructura cuadrangular donde sus calles son canales por donde navegan fantásticas embarcaciones cuya imagen nos trae al pensamiento esas urbes "del deseo" o "de la memoria", descritas por Italo Calvino en su admirable texto dedicado a las ciudades invisibles.

El tema del viaje ha sido siempre uno de los motivos que han suscitado una mayor predilección entre los escritores y pintores. Viajes en el tiempo, en el espacio, a través del cuerpo humano, de la memoria, viajes metafísicos..., han sido reflejados como experiencia vivida o imaginada. En la pintura de Remedios Varo el viaje es, junto con el destino y la alquimia, una de sus obsesiones más apreciables, siendo justificado tanto por causas personales, concretamente biográficas, como, sobre todo, por el anhelo de trascender hacia un conocimiento superior, que impulsó toda su existencia como antídoto a ese estado permanente de soledad espiritual. Como afirma Fernando Pessoa, "para viajar basta con existir". Igual que el escritor portugués, Remedios viajó sin moverse de su sitio; la imaginación y el deseo fueron el medio para alcanzar sus objetivos.

Todo viaje responde a una necesidad material o interior. La obra de Remedios está llena de estas exigencias que nos transmiten sus inquietudes y experiencias. Es una primera lectura, qué duda cabe, que las propias vivencias de la artista en sus continuos traslados de un lado para otro, desde su infancia a la madurez - nacimiento fortuito en Anglés, Algeciras, Madrid, Barcelona, París, Caracas, México- hay que verlos como una de las causas que explican en parte, esa presencia del tema del viaje en bastantes cuadros. Sin embargo, razones mucho más profundas fueron las que impelen a esa búsqueda que tiene en la imagen del viaje su justificación más exacta y acentuada. Peregrinos, exploradores y viajantes, recorren caminos y senderos, produciéndose en el tránsito encuentros maravillosos o descubrimientos insospechados, como el de esos navegantes que desde su fabulosa embarcación divisan un extraño objeto luminoso que reclama su atención: Hallazgo, 1956. Remedios al comentar esta composición dice textualmente: "Los viajeros representan gentes que buscan llegar a un nivel más alto espiritual". En esta aspiración a un conocimiento más elevado, que tiene en la espiritualidad su vía de acceso, reside el porqué de muchos periplos que toman en la iconografía del viaje su simbolismo más paradigmático.

El viaje no es mera traslación en el espacio, sino ejercicio de iniciación hacia la sabiduría y la autorrealización. Los personales que emprenden esta 
odisea espiritual lo hacen a través de distintos medios y circunstancias, siendo el trayecto fluvial uno de los más empleados: Exploración de las fuentes del río Orinoco, 1959. Viajes por tierra en sus estaciones más rigurosas: La expedición del agua áurea, 1962, o incluso por las nubes: La huida, 1962. En el primer ejemplo, la búsqueda del agua ha determinado el viaje como elemento de regeneración y elixir contenido en una copa de cristal que mana ininterrumpidamente para aquellos que han sabido encontrarla. Seguramente una de las obras que mejor expresan el sentido simbólico de viaje iniciativo en pos de la iluminación sea Ascensión al monte análogo, 1960, título de la novela homónima de René Daumal y que Remedios nos describe de la forma que sigue: "Como veis, ese personaje está remontando la corriente, solo, sobre un fragilísimo trocito de madera y sus propios vestidos le sirven de vela. Es el esfuerzo de aquellos que tratan de subir a otro espiritual" (2). Como en la anterior explicación sobre el cuadro Hallazgo, Remedios insiste en el logro de un nivel espiritual que conlleva siempre una gradación, siendo en la representación de la montaña donde tiene su plasmación más explícita desde el punto de vista iconológico. Esta misma idea de elevación espiritual se encuentra en Flautista, en el que ese nuevo Hamelín encantador de piedras, tiene la propiedad mágica de hacer que mediante el sonido se vayan superponiendo y se construya una torre octogonal en forma de zigurat. La torre guarda idéntico significado que la montria, un ascenso espiritual a través del conocimiento, representado aquí simbólicamente por esas piedras-fósiles que son la memoria y las depositarias de la sabiduria.

Otro de los temas que de un modo más continuo aparece en la producción de Remedios, es el de la alquimia expresada en una simbología ocultista perfectamente visible en argumentos e imágenes. Conociendo su biografía, existen datos suficientes para señalar el interés que siempre demostró Remedios por lecturas y autores relacionados con la ciencia, lo esotérico, lo mágico y lo místico (3).

Surrealismo y alquimia descansan sobre un mismo principio, esto es, son fundamentalmente un medio que tiene como objeto la transformación y el 176.

(2) Remedios Varo, recogido en el libro De Roger Callois, Octavio Paz y Juliana González, pág.

(3) Entre los autores preferidos por Remedios Varo estaban René Daumal, Hermann Hesse, Carl Gustav Jung, Fred Hoyle, Aldous Huxley, Isaac Asimov, P. D. Ouspensky, etc. Sus lecturas constituyeron en muchos casos el punto de partida e inspiración de varias composiciones donde la alquimia y la ciencia son protagonistas. 
cambio; primero siguiendo los ambiciosos consejos de Rimbaud y Marx referidos a la vida y al mundo, el segundo teniendo la materia como metáfora práctica en busca de la perfección. Este doble planteamiento aparece en la obra de Remedios, pudiendo apreciarse una evidente afinidad entre uno y otro. Si tenemos en cuenta que los surrealistas, al igual que los científicos, vieron en la pintura surrealista un sistema de conocimiento o investigación, observamos que tanto desde el punto de vista filosófico como artístico, la obra de Remedios ejemplifica bien la tarea del artista como alquimista. Sus innatas condiciones anímicas, por las que podría establecer y vislumbrar interconexiones secretas con la naturaleza y los objetos que le rodeaban, así como por el hecho de ser mujer en el sentido surrealista, por el cual ésta es especialmente proclive a ser la gran mediadora entre la realidad y el misterio, Remedios se nos presenta como la gran alquimista de la pintura surrealista. El propio oficio de pintor en la soledad del estudio mezclando colores y metamorfoseando las formas, guarda semejanza con el alquimista cuya imagen en su laboratorio junto a retortas y alambiques aparece en los cuadros de Remedios: La ciencia inútil o el alquimista, 1958.

La idea común de que el alquimista tiene como fin hallar oro, a través de la trasmutación de los metales es un enunciado simplista. En realidad, dicha labor encierra todo un proceso simbólico en busca de la perfección y la iluminación, que comporta en la persona una experiencia moral y espiritual. La misma imagen del oro no es más que un símbolo de luz y superioridad. Esta persecución del alquimista por lo perfecto, se puede comprobar en la propia pintura de Remedios, una de cuyas características más notables es precisamente la perfección manifestada en el virtuosismo técnico con el que pinta sus cuadros (4).

Según Mircea Eliade, las sustancias minerales, en su proceso de mutación, pasan por fases de "sufrimiento", "muerte" y "renacimiento", lo que viene a significar que la materia en el crisol alquimista es considerada como órgano vivo que posee una evolución equiparable al desarrollo del hombre, es decir, nace, crece y muere, y según todas las religiones históricas, renace más tarde. Esta misma trayectoria de creación, encuentro y renacimiento, está presente en la obra de Remedios. El alquimista, al igual que el artista, es un demiurgo y como tal aspira, siguiendo a Eliade, al "viejo sueño del Homo faber de colaborar al perfeccionamiento en la materia

(4) Véase Lourdes Andrade "Remedios Varo" y la "Alquimia", México en el Arte, N.9 14, Otoño, México, 1986. 
asegurando al mismo tiempo su propia perfección". Esta colaboración en el caso de Remedios, tiene como instrumentos a la imaginación, la intuición, el deseo y la libertad, que aplicados al lienzo contribuirán a conseguir la "obra maestra" a la par que el mejoramiento espiritual (5).

Entre los cuadros que de un modo más representativo reflejan las teorías expuestas, pueden citarse el ya mencionado La ciencia inútil o el alquimista, donde aparece un personaje cubierto con el propio pavimento del suelo ajedrezado en plena tarea de trasmutación de la materia, manipulındo un complejo sistema de ruedas y poleas cuyo movimiento hace girar un eje y a su vez unas campanas, produciendo con la vibración de sus sonidos una disolución líquida en la armósfera que es recogida mediante filtros en unas botellas después de haber pasado por la consiguiente retorta. En la Creación de las aves una mujer-lechuza - símbolo de la sabiduría- consigue mediante sustancia cromática, producida en un alambique de forma ovoide, dar vida a los pájaros que está pintando. Obsérvese que el extremo del pincel roza una de las cuerdas del pequeño violín que a modo de collar pende del cuello del personaje, haciendo referencia con ello al poder creativo del sonido defendido por las teorías sufies de Gurdjieff, uno de los escritores admirados por Remedios. En otro de los cuadros, Planta insumisa, 1961, se representa a un científico trabajando sobre unas plantas, las cuales tienen ramas como signos de fórmulas matemáticas que aparecen también en el propio pelo del investigador, asimismo el formato del cuadro adopta la forma de huevo en una clara intención simbólica de la imagen universal y al principio creativo.

Aparentemente y en una primera impresión, la obra de Remedios Varo puede conducir a una conclusión equívoca, dado su sugestivo poder de belleza formal, olvidando, como he tratado de señalar, que casi siempre detrás de ella se oculta un significado profundo y trascendente. Su obra es portadora de ideas que mediate la metáfora visual del "viaje" como iniciación, la "alquimia" como trasformación del individuo o el "destino" como preparación de un más allá, encierra y exigen una compenetración que sólo aquellos que saben ver podrán captar y gozar de una de las creaciones más admirables de una artista cuya actitud frente a la vida, fue quererla transformar mediante el postulado surrealista, aunque esto lo hiciese de forma silenciosa.

(5) Véase Miecea Eliade. Herreros y Alquimistas, Ed. Alianza Editorial, Madrid, 1986. 


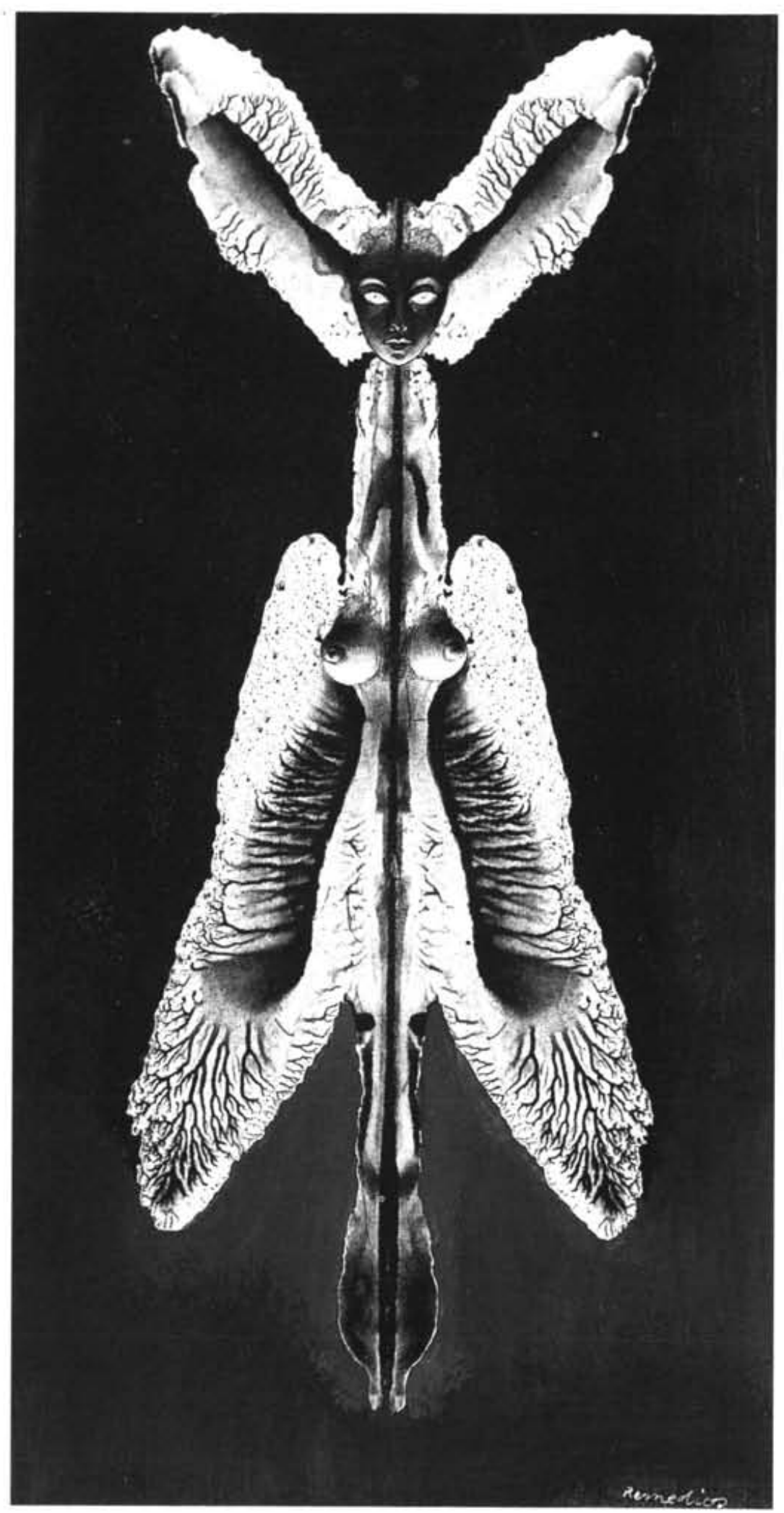

"Mujer o el Espíritu de la Noche", 1952 


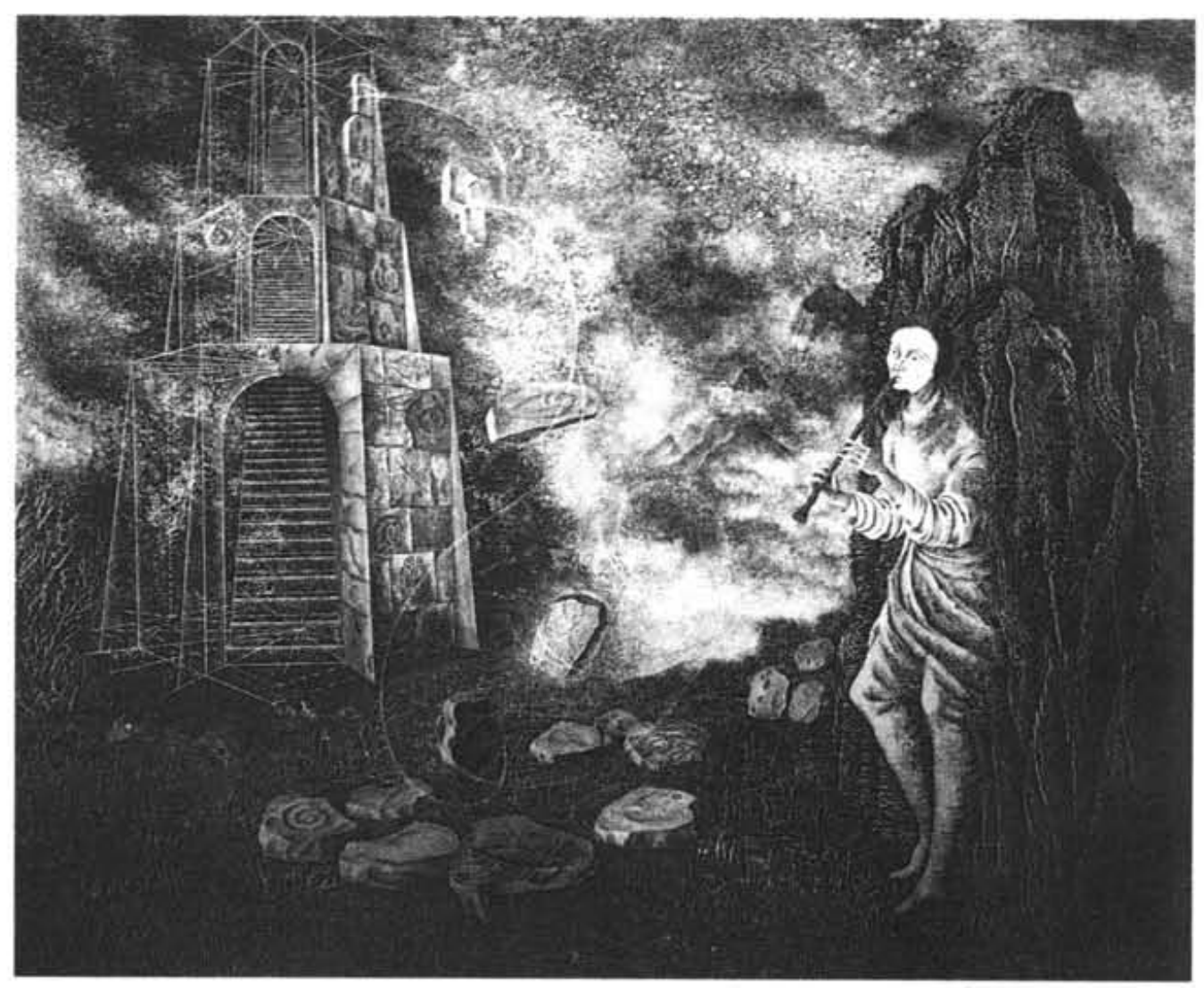

"El Flautista", 1955. Remedios Varo

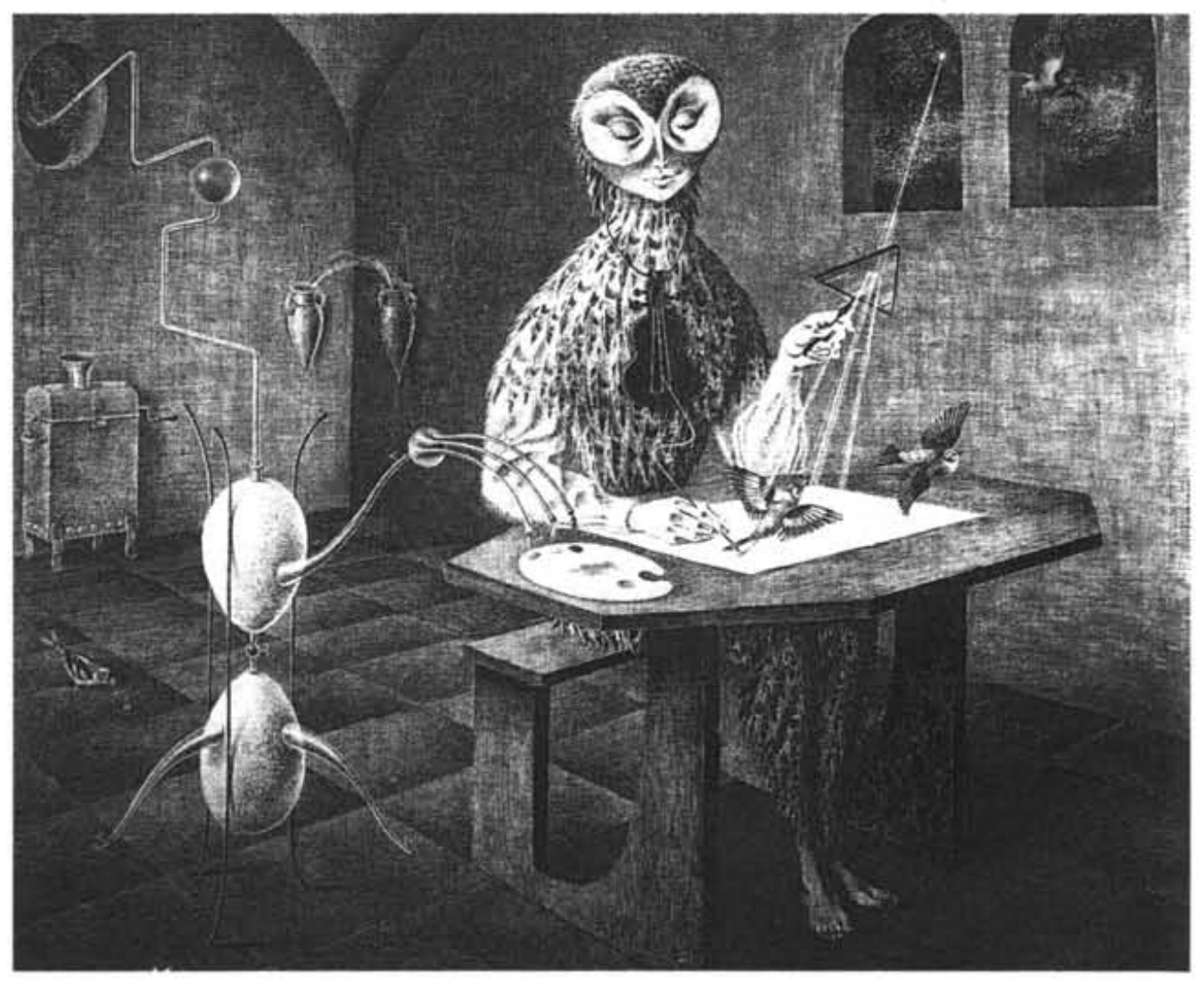

"La Creación de las Aves", 1958. Remedios Varo 


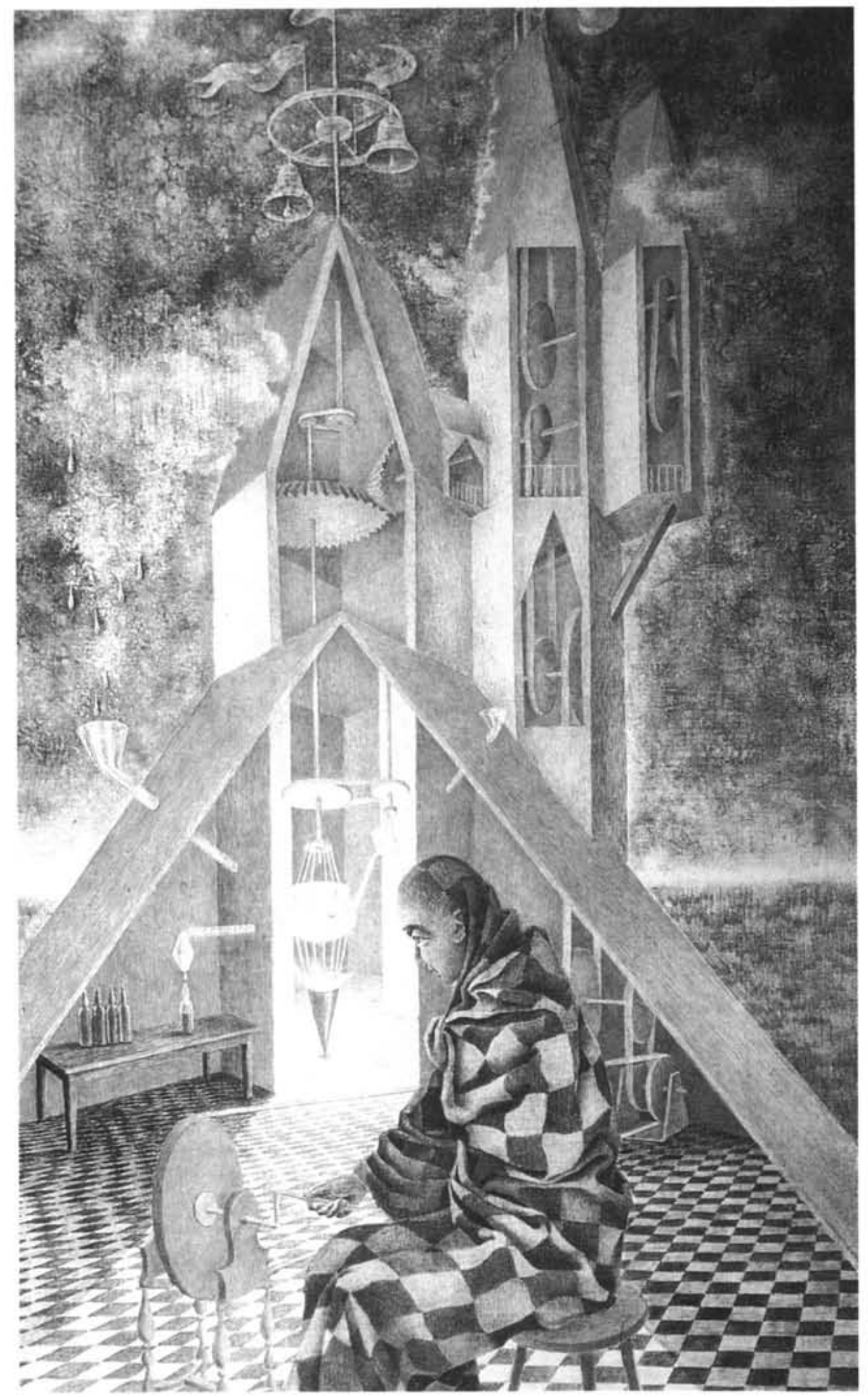

"La Ciencia inútil o el alquimista", 1958. Remedios Varo 


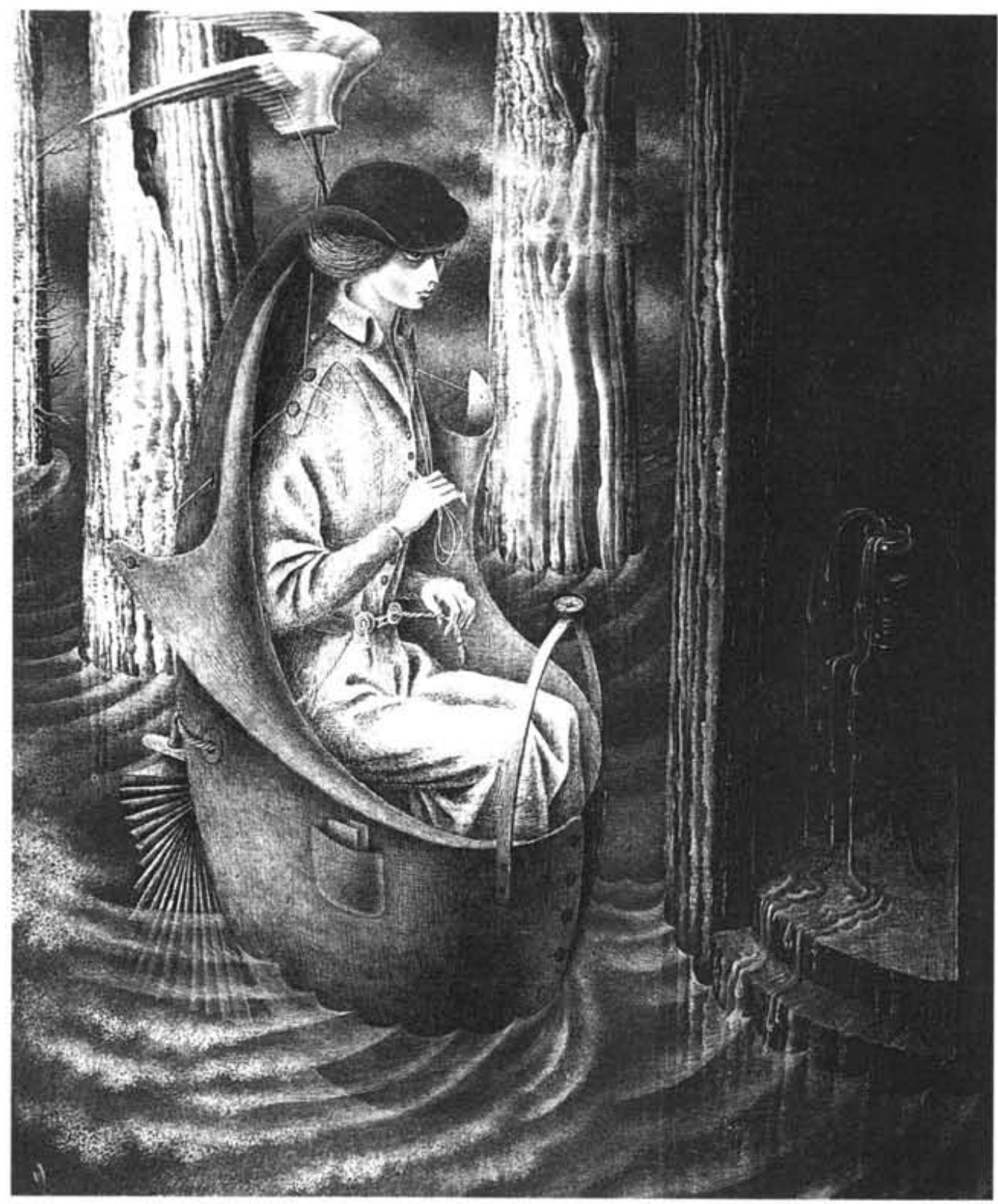

"Exploración del río Orinoco", 1959. Remedios Varo 


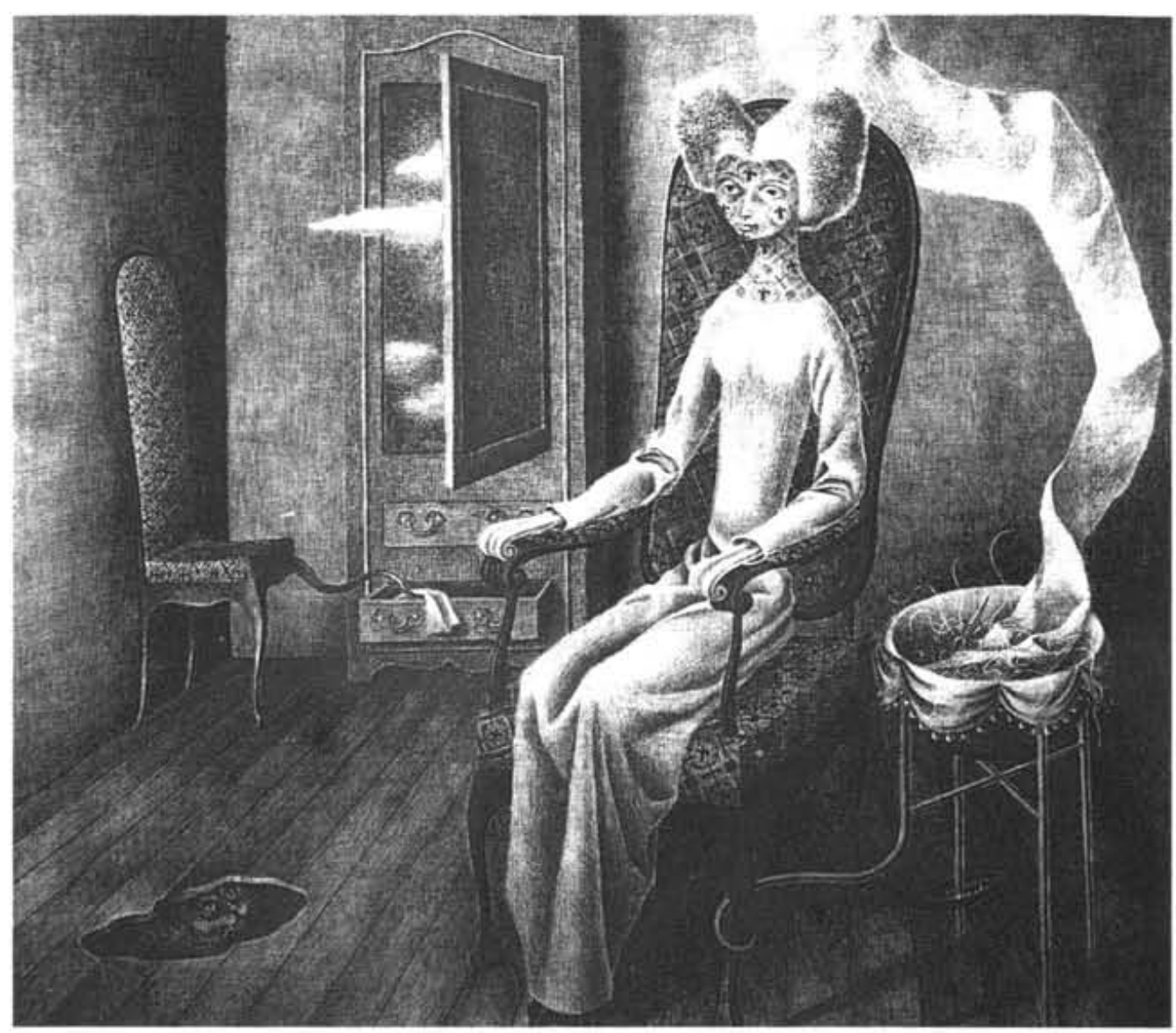

"Mimetismo", 1960. Remedios Varo

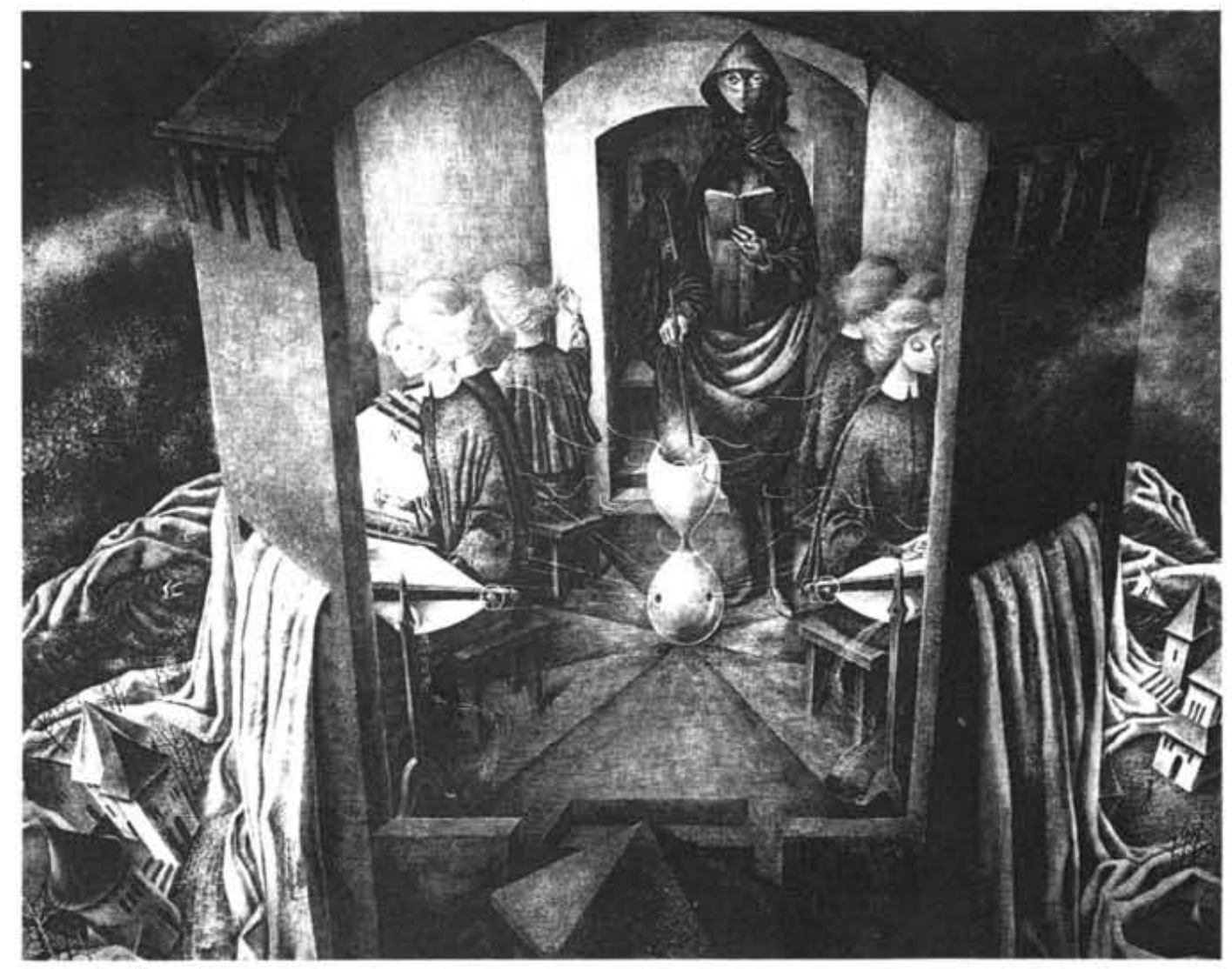

"Bordando el manto terrestre", 1961. Remedios Varo 


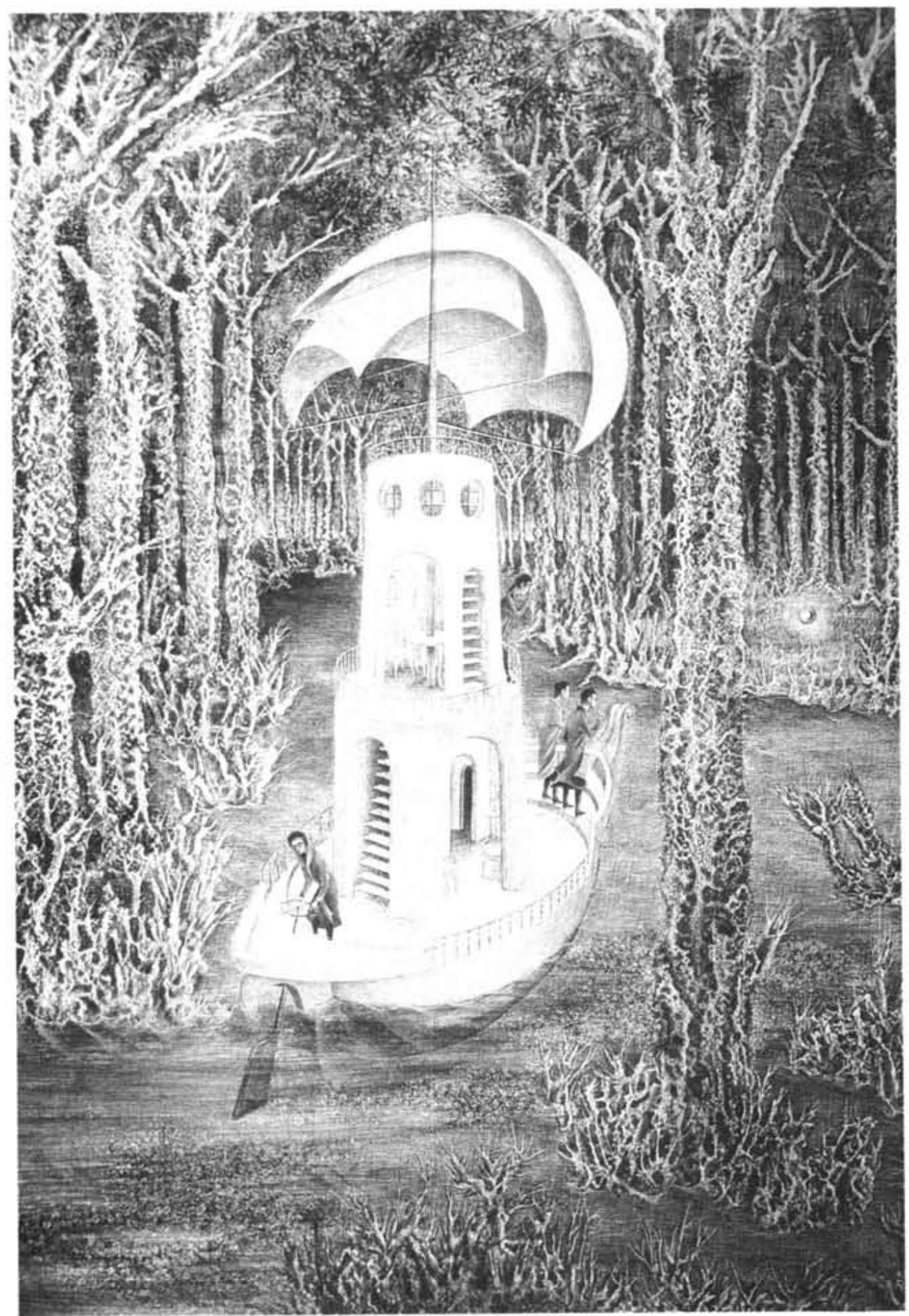

"El Hallazgo", 19. Remedios Varo 


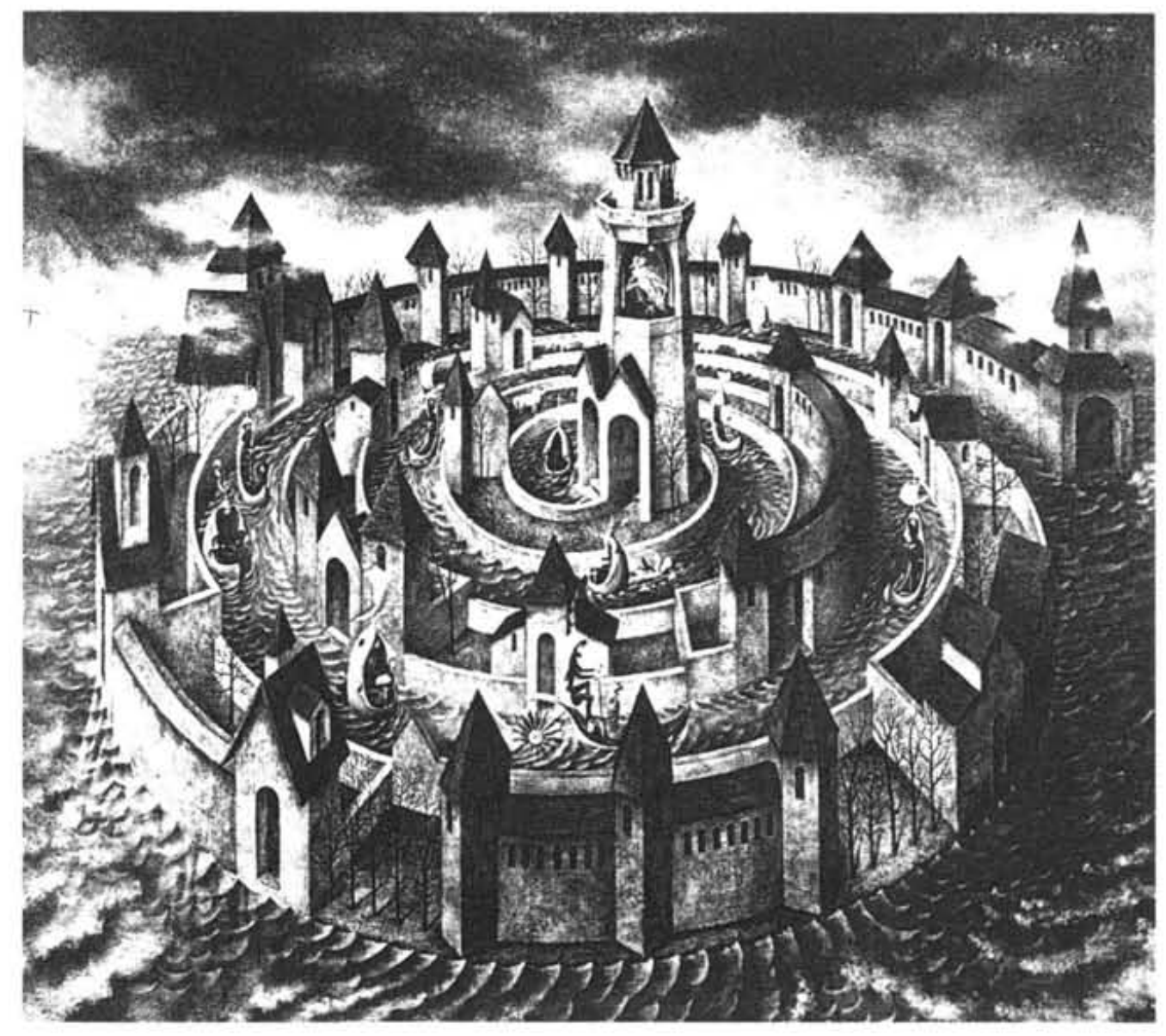

"Tránsito en Espiral", 1962. Remedios Varo 